\title{
Re-recognition on the Higher Dance Education in the Age of MOOC
}

\author{
Li CHEN \\ School of Music and Dance \\ Jiangxi University of Technology \\ Nanchang, Jiangxi,330098 China
}

\begin{abstract}
MOOC becomes very popular all over the world within just two years. With the development of MOOC, colleges and universities are full of passion and challenges. Its emergence is an important turning point of higher education reform. In this paper, the characteristics and advantages of MOOC are summarized, and then the opportunities and challenges in the age of MOOC to the dance education of colleges and universities are analyzed, and then the aspects such as course setting, organizational model, and teachers are recognized, in order to effectively discuss the new teaching model and especially course setting in the dance education of colleges and universities.
\end{abstract}

\section{Keywords- MOOC; Courses; Dance Education; Reform}

\section{INTRODUCTION}

MOOC (Massive Open Online Course) becomes very popular all over the world within just two years. With the development of MOOC, colleges and universities are full of passion and challenges. It is necessary for colleges and universities to rethink their own position and how to cope with the upcoming education storm. Experts predict that education will be one of the industries changed by the Internet in the future.

Zhiming LI, director of the Science and Technology Center of the Ministry of Education, says that MOOC means campus fence is being broken and the sharing of the high quality education resources has become a must of the times; the college and university functions in the traditional sense will disruptively change, and education will be beyond the existing educational scope and will become the important carrier of the national culture and soft power output. Fang LU, vice president of Fudan University, thinks that MOOC lies in the "discussion on the educational reform and new teaching model" practical in the depth of higher education mechanism, but not in the sharing of campus's external quality resources. The important role of information technology in education has been very early recognized by all walks of life, and also "information technology plays a revolutionary influence on education development and must be highly focused" has been written into the "the National Medium and Long-term Education Reform and Development Plan Outline (2010-2020)". Since educational informationization was greatly developed from the 1990s, however, only MOOC was seriously taken by the leaders of many first-class universities in the application of information technology education. The Ministry of Education has intensively promoted the construction of MOOC all over the country and MOOC will become the main form of network courses [1].

\section{THE CHARACTERISTICS AND DEVELOPMENT OF MOOC}

MOOC has several notable characteristics: teaching activities hybridization - reversal class, audience scaleacross time and space, learning personalization-adaptive, and interactive communication-full interaction. Autonomous learners will be willing to embrace the future and invest themselves beyond all doubts. "The emergence of MOOC is a cut-off point of the Internet education application, before which the focus of the network education was placed on the internal levels of the open courses, and after which MOOC develops into a new college and university course implementation model under the background of exploring the open Internet and makes the deep-rooted traditional classroom organization and management model moved", said Dr. Xiuli Zhuang, education technology researcher of Beijing Normal University.

The characteristics of MOOC are concluded as follows: (1) free to obtain resources; (2) no limits to the number of learners; (3) free for learners to adjust the learning time and schedule, reflecting the personalized management.

Compared with the public video classes, MOOC is greatly different.

The open online courses in the foreign countries are almost all popular courses in schools, and school professors are almost the experts of the fields. News indicates that the cost of Yale University to produce an open course is up to $\$ 30,000 \sim 40,000$, while the cost of Massachusetts Institute of Technology to produce an open course is about $\$ 20,000$, and also resources are provided for free. The United States has become a pioneer in free and open courses [2].

\section{THE CORE STRENGTHS OF MOOC}

MOOC emerged in the United States in 2010 and got an explosive growth in 2012. New York Times said 2012 was the year for MOOC. In 2011, Introduction to Artificial Intelligence, which was offered by professor Sebastian of Stanford University to graduate students, was released on the Internet, so that more than 160,000 students from over 190 different countries were attracted and also 20,000 of them completed the course, making a new chapter of MOOC 
started. Why does MOOC have such a great influence? What factors are making MOOC so appealing? The influence of MOOC mainly sources from reputable schools, reputable teachers, boutique courses, open, free, etc.

A learner, if the conditions are available, naturally hopes to follow the best teachers in the world to learn. For this reason, it is instinct for people to chase after reputable schools and teachers, while such an opportunity is produced by MOOC. The factor is followed by "boutique courses", "open", and "free" in turn [3].

\section{THE ENLIGHTENMENT FROM MOOC ON THE DANCE EDUCATION REFORM OF COLLEGES AND UNIVERSITIES}

The structural change of the higher education field is necessary, which is an only issue to occur sooner or later. MOOC itself is not omnipotent, but it may be a very good opportunity. In such a challenge and opportunity, how does dance education as an important subject of higher education to cope with MOOC?

\section{A. Re-recognition on Course Setting}

In terms of the dance course setting, courses are constantly adjusted according to the educational positioning and direction in addition to the conventional courses, in order to let the personnel training and course setting further keep pace with the market. The final evaluation standards will be subject to knowledge acquisition and ability manifestation. In the age of MOOC, it is first necessary to know well how to produce a link with MOOC in order to share the course resources online.

First, dance study and dance performance majors are offered by many Chinese colleges and universities successively in recent years, but these are the choices of a small group. The scope of the professional dance education is very narrow, and also its popularization among the public is greatly restricted to some extent.

Second, dance course is different from the ordinary courses, and it takes action language as the first element. Therefore, the design ideas in the MOOC platform must be definite and explicit, and top priority should be given to the easy-to-understand and easy-to-popularize basic courses, so that more and more students majoring dance or taking dance as a selective course are promoted to share the resources in a timely manner.

Third, experts can be employed to make the relevant demonstrations complying with the law of dance courses and also the MOOC design concept; the characteristics of the courses in different subjects should be highlighted in order to find out the points such as the effective utilization of time (rhythm) and space (environment) and the analysis of culture for possibly combining the online courses.

Third, the online courses complying with the law of the MOOC platform and featuring dance culture can be set up for students to choose in terms of the analysis on the most basic courses, combining the practice with theory according to the teaching concept, and using the effective teaching methods.
The major courses such as dance history and theory courses that are the most suitable into the MOOC platform should be chosen. With regard to the dance courses supported by video, the combination with the history course has considerable advantages.

First of all, there has been an accumulation of experience in the traditional teaching method of history course, and there have been rich contents to display with video in both course classification and teaching methods. Secondly, the major teachers in history course possess a solid foundation in the dialogue and exchanges with the students and rich experience in promoting courses and student interaction, and also can provide an effective solution according to different types of problems, so as to meet the multiple choices of the students.

\section{B. Re-recognition on the Teaching Model}

In terms of the current big dance courses in common colleges and universities of China, dance courses were mostly orally taught by their own teachers in a traditional sense and few teachers were fired from other schools to teach dance courses, except that a small number of institutions of higher learning will fire the teachers from famous and large colleges and universities in order to share the resources. Then, there might be a problem. That is, some schools are limited in the teaching resources and unable to offer the very professional major courses or the teaching objective is not achieved because the teaching level is limited though the courses are offered, so that a good teaching effect is not played [4]. With the arrival of the age of MOOC, a new train of thought is provided for the dance course setting in all large colleges and universities.

Certainly, everything depends on the learner's initiative no matter how the courses are organized. Although a lot of students are very lively in MOOC at present, whether they will be very serious to complete the relevant learning courses is still a problem worthy of studying.

\section{Re-recognition on Teachers as Subjects}

The key to change is as follows: the reversal of classroom teaching - the conventional classroom teaching is that students listen to the explanation from teachers at classroom and finish corresponding reviews and preview tasks after class; the online classrooms make the traditional classroom teaching model subverted, and students can learn the knowledge system in the home and make practices at school classrooms, and also teachers and students can answer questions together. In this online classroom, the high quality teaching resources can be obtained in a very cheap way, so that the specialty of the teachers is impacted.

Commonly, teachers are understood as individuals, and they should independently finish the tasks including the courseware preparation and the on-site equipment control in the process of concrete classroom teaching although there are auxiliary teaching staffs in school. In other words, a support team is needed by every teacher during the teaching period, and this is not bearable for colleges and universities at present. 
Although all colleges and universities encourage teachers to make wide-ranging cooperation in the teaching and research field, they are relatively independent in the field of teaching. Every teacher, regardless of the teaching level, can fully explain their own views and opinions in their own platform, and do not need to worry about being replaced by other teachers. However, the majority of the online courses are taught by famous masters in the age of fully implementing MOOC, and it is necessary for the teachers to comprehensively renew and re-know themselves; some teachers are changed from the major lecturers to the assistants, and they need to adjust their own psychological gap for constantly improving themselves.

Then, how do teachers do in the age of MOOC? They are first necessary to become the "pioneers" of the study, and act as learners with students together under the context of the lifelong education, in which teachers are the pioneers of the study. With the growth of the personalized teachers, the students with significant personality can be trained. Then, the idea of "educate people" should be fully implemented, in which the reduction of burdens is taken as an important target in education.

In the age of MOOC, a new hope is offered to the higher education reform. It plays a significant effect on promoting the balanced development of the education, education fair, teaching model innovation, and the quality of education. However, MOOC also is not omnipotent and not all learners can become an active learner after accessing to the MOOC. To higher education, MOOC means more opportunities, and may help really realize the great openness of education under the impetus of MOOC, so that a new higher dance education model is created

\section{REFERENCES}

[1] MOOC's Enlightenment to Higher Education Reform. Guangming Daily. November 2013.

[2] Ning ZHONG. How Does Continued Dance Education confront with the Arrival of MOOC's Age? Dance, January 2014.

[3] Zuoli WANG. MOOC, A Storm of Education Is Coming? China Education Network, May 2013.

[4] The Impact of MOOC Age on Education. SEVENLEAF, July 2013. 